\title{
O SOFRIMENTO NA RELAÇÃO DOS SERVIDORES TÉCNICOS ADMINISTRATIVOS DA UNIVERSIDADE FEDERAL DE PERNAMBUCO COM A ORGANIZAÇÃO DO TRABALHO
}

\author{
THE SUFFERING IN THE RELATIONSHIP OF THE FEDERAL \\ UNIVERSITY OF PERNAMBUCO'S TECHNICAL ADMINISTRATIVE \\ SERVERS WITH THE WORK ORGANIZATION \\ Cecilia Melo Calado ${ }^{1}$ \\ Denilson Bezerra Marques ${ }^{2}$
}

1

Graduada em Secretariado pela Universidade Federal de Pernambuco (2005). Experiência na área de Administração, com ênfase em secretariado. Atuou em diversões órgãos públicos. Pós-graduada em Gestão Pública pela UCDB (2013) e Mestra em Gestão Pública pela Universidade Federal de Pernambuco (2017).

2

Psicanalista com graduação (1995) e mestrado (2000) em Administração e doutorado (2006) em Sociologia, ambos os títulos acadêmicos pela Universidade Federal de Pernambuco. Professor Associado 2 do Departamento de Ciências Administrativas da Universidade Federal de Pernambuco e Coordenador do Mestrado em Gestão Pública (MGP).
RESUMO: A presente pesquisa investigou o sofrimento na relação de servidores técnicos administrativos da Universidade Federal de Pernambuco com a organização do trabalho. Procurou conhecer a história pessoal e profissional dos servidores para identificar se existe sofrimento psíquico no desenvolvimento de suas funções e, sobretudo, compreender se tal vivência tem relação com a organização do trabalho. Adotou-se uma abordagem qualitativa com a utilização da entrevista individual semiestruturada para a coleta de dados. Apreendeu-se que o servidor da UFPE, de modo geral, traz para a prática profissional vários elementos que fazem parte da construção da sua história de vida, os quais se refletem na sua relação com a organização do trabalho. Pôde também extrair registros diversos de insatisfação, prazer, incômodo, sofrimento psíquico e, em alguns casos, adoecimento, ligados em sua maioria a aspectos da organização de trabalho.

PALAVRAS-CHAVE: sofrimento; organização; servidor; UfPE

ABSTRACT: The present research investigated the suffering in the relation of Federal University of Pernambuco's technical administrative servers with the organization of work. It sought to know the personal and professional history of the servers to identify if there is psychological suffering in the development of their functions and, above all, to understand if such experience is related to the work organization. A qualitative approach was adopted with the use of the semi-structured individual interview for data collection. It was observed that the UFPE server, in general, brings to professional practice several elements that are part of the construction of its life history, which are reflected in its relation with the organization of work. It was also able to extract diverse records of dissatisfaction, pleasure, discomfort, psychic suffering and, in some cases, illness, mostly related to aspects of work organization.

KEYWORDS: suffering; organization; server; UFPE

\section{INTRODUÇÃO}

Foi longo o percurso percorrido na história até que o trabalho fosse reconhecido como fator responsável por alguma espécie de dano para a saúde psíquica do trabalhador. No âmbito da gestão pública brasileira, no entanto, ainda há muito que se estudar sobre o prejuízo real na qualidade do serviço prestado em razão do número dos servidores afastados de suas atividades por motivo de doença. Se existe um número expressivo de agentes adoecendo nas instituições públicas, significa 
3

Christophe

Dejours é psicanalista, doutor em Medicina, especialista em medicina do trabalho e em psiquiatria. É considerado o pai da Psicodinâmica do Trabalho. que o Estado em suas diferentes esferas tende a dispor de um quadro de pessoal defasado e inadequado para executar seu trabalho, administrar as demandas advindas da sociedade e cumprir suas funções.

Sendo assim, surge uma preocupação que se apoia na teoria formulada por Dejours 3 (1994), principal teórico dessa pesquisa, de que mesmo sendo um fator importante para a cidadania e a integração social do indivíduo, o trabalho é capaz de provocar sofrimento mental e até mesmo gerar adoecimento. Apesar do ambiente de trabalho, conforme o autor, representar um campo propício para a manutenção da saúde, nos casos em que o sofrimento é administrado com criatividade, também pode se revelar um espaço de estímulo ao desenvolvimento da doença, quando o trabalhador não consegue superar o sofrimento.

Todavia, normalmente parece existir um desinteresse por parte das organizações em investigar o sofrimento mental dos trabalhadores. Nesse sentido, o procedimento mais comum é desconsiderar a possibilidade de sua existência. Quando realmente precisam buscar respostas para as doenças e os insucessos operacionais dos trabalhadores, as empresas se utilizam de outros argumentos. Seligmann Silva (1994) assevera que a gestão encontra muito embaraço para identificar as causas de determinadas falhas do trabalho prestado, que são decorrentes do sofrimento mental engendrado pela situação de trabalho e, geralmente, de modo mais específico, pela organização prescrita para o trabalho.

Desse modo, esta pesquisa caminho pautando-se na opinião defendida por Dejours de que o sofrimento psíquico no trabalho faz um apelo à resposta visando, na etiologia do sofrimento, outro determinante ligado à situação mesma do trabalho. Ora, "a organização do trabalho não é singular; ela engaja todos os atores da instituição. Sua investigação passa pelos coletivos do trabalho" (DEJours, 1994, p. 86). Por isso mesmo, estabeleceu-se como uma das ferramentas adequadas aos objetivos deste estudo a entrevista semiestruturada, realizando-se escuta atenta e análise dos relatos dos técnicos administrativos da UFPE.

É necessário conhecer as experiências vividas nesse âmbito pelos servidores na Universidade Federal de Pernambuco, bem como, aproveitar alguns dos registros por eles deixados através dos comportamentos apurados pelos sistemas e bancos de dados da instituição, tais como faltas injustificadas e licença para tratamento de saúde (Transtornos Mentais e Comportamentais - TMC).

Portanto, à luz da Psicodinâmica do Trabalho foram analisadas informações sobre a vivência pessoal e profissional dos servidores entrevistados para identificar as possíveis fontes de sofrimento psíquico na relação com a organização do trabalho dentro da UfPE. A ideia central foi verificar se o sofrimento da história de vida pessoal do servidor, como garante Dejours (1994), se relaciona com o sofrimento vivenciado no âmbito profissional, além disso, examinar se o suposto sofrimento vivenciado no âmbito profissional se relaciona com o elemento organização do trabalho. 
4

Cf: $<$ http://sinus.org. br/2014/wp-content/ uploads/2013/11/OMSGuia-Online.pdf>. Acesso em 12 de junho de 2015.

\section{FUNDAMENTAÇÃO TEÓRICA}

\section{PERCURSO HISTÓRICO DA RELAÇÃO ENTRE \\ TRABALHO E SAÚDE-DOENÇA NO BRASIL}

Pensar sobre a relação que existe entre trabalho e saúde ou trabalho e doença, passa primeiramente pelo campo da conceituação de saúde e doença para depois demonstrar a evolução do tratamento dispensado ao tema no decorrer do tempo. De acordo com a Organização Mundial

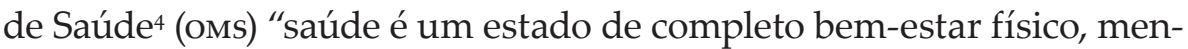
tal e social e não somente ausência de afecções e enfermidades".

No entanto, destaque-se a ressalva que Dejours faz a essa definição de saúde estabelecida pela oms, argumentando que parece impossível conceituar com exatidão esse estado de bem-estar e de completo conforto. Não se sabe, segundo o autor, o que é, e, crê que não haja esclarecimentos significativos sobre a questão. Por fim, assente que "no fundo, esse perfeito e completo estado de bem-estar não existe" (DEJOURS, 1982, p. 2).

Canguilhem, por outro lado, aponta um modo diferente de apreender a saúde. $\mathrm{O}$ autor atribui à saúde exatamente o poder ou a capacidade do homem de conseguir adoecer e sair do estado patológico. Seria o modo de reação, o modo e a força com que o indivíduo responde às várias dificuldades e mudanças na sua vida. Nesse contexto, a saúde se reflete na maneira como o sujeito encara as novas experiências, ou segundo ele, a "margem de tolerância ou de segurança que cada um possui para enfrentar e superar as infidelidades do meio" (CANGUILHEM, 2009, p. 148). Assegura o autor que quem determina o estado da doença é o sofrimento, a dor, o prazer, ou seja, os valores e sentimentos confessados pelo corpo subjetivo vítima da patologia.

Dejours apontava, ainda na década de 80, que haviam sido acumuladas experiências e novos conhecimentos capazes de modificar essa definição de saúde, ou de fazê-la progredir. Enxergava três elementos transformadores do conceito de saúde: a fisiologia; a psicossomática e a psicopatologia do trabalho. Em suas palavras, a fisiologia é "a análise do funcionamento do organismo, as regras que asseguram seu equilíbrio e sua sobrevivência"; a psicossomática, "as relações que existem entre o que se passa na cabeça das pessoas e o funcionamento de seus corpos" e a psicopatologia do trabalho, o estudo que vai mostrar que "o trabalho é um elemento fundamental para a saúde" (DEJOURS, 1982, p. 2).

No Brasil, que por mais de três séculos foi colônia e manteve a mão-de-obra escrava, como elucidam Silva et.al. (1994), não se pensava em relacionar trabalho e saúde na administração pública e nem para a classe médica isso se configurava possível até certo tempo atrás. Os primeiros pensamentos sobre o assunto como interesse público e social só começaram a ser considerados a partir do século XIX. Até então, o país preocupava-se apenas com as doenças de quarentena, tais como cólera, peste e febre amarela, porque limitavam a produção no setor agroexportador e o comércio de modo geral. Por 
5

Cf: <http://www2. camara.leg.br/legin/fed/ decret/1910-1919/decreto3724-15-janeiro-1919571001-publicacaooriginal94096-pl.html $>$. Acesso em 15 de junho de 2015.

6

Cf: <http://www.planalto. gov.br/ccivil_03/decretolei/1937-1946/Del7036. $\mathrm{htm}>$. Acesso em 15 de junho de 2015.

7 Cf: <http://presrepublica. jusbrasil.com.br/ legislacao/128593/lei5161-66>. Acesso em 15 de junho de 2015.

\section{8}

Cf: <http://www.camara. gov.br/sileg/integras/839945. pdf $>$. Acesso em 15 de junho de 2015. isso, os estudos pioneiros foram direcionados para a realidade de fábricas específicas e das minas.

Ao tratar do assunto das normas legais de proteção à saúde do trabalhador, Teixeira (2007) aponta que a primeira lei sobre acidentes do trabalho no Brasil foi o Decreto Legislativo $\mathrm{n}^{\mathrm{0}} 3.7^{2} 4^{5}$, aprovado em 1919, que regulava as obrigações resultantes dos acidentes no trabalho. Entretanto, chama a atenção para o fato de que desde a citada lei acidentária, as doenças provocadas pelo trabalho do empregado são sempre equiparadas a acidente do trabalho.

Em 1944 o Presidente Getúlio Vargas decretou a lei de acidente do trabalho (Decreto-Lei $\mathrm{n}^{\mathrm{o}} 7.036^{6}$ ) com o esforço do Ministério do Trabalho, Indústria e Comércio. Antes, porém, ainda em 1934, surgiu a figura do 'inspetor-médico do trabalho', cuja nomeação ficava a cargo do Ministro do Trabalho, e foi criado também o Serviço de Higiene do Trabalho, na Inspetoria Nacional do Trabalho.

Entre as décadas de 30 e 60 foi produzido bastante conhecimento acerca do tema Patologia do Trabalho, sempre voltado às questões físicas e direcionado a áreas muito específicas de trabalho, especialmente às minas, às fábricas e doenças que lhes cabiam. Importa nesse momento explicar que o termo Patologia do Trabalho é "o estudo do sofrimento, dano ou agravo (pathos) à saúde, causado, desencadeado, agravado pelo trabalho ou com ele relacionado" (MENDES, 1995, p. 35).

É interessante relatar que a orT, além de criar a lista de doenças do trabalho, organizou uma coletânea de textos sobre Patologia do Trabalho e prevenção, e lançou a enciclopédia Organização e Saúde, em francês e inglês, revista e ampliada em 1971. Em 1983, ganhou o status de enciclopédia sobre Saúde e Segurança Ocupacional e foi traduzida para muitos idiomas.

Em 1966, no Brasil, foi criado a Fundacentro, através da Lei no 5.161/19667. Trata-se de uma instituição governamental que atua na área de pesquisa científica e tecnológica relacionada à segurança e saúde dos trabalhadores, considerada marco no estudo da saúde ocupacional no país. Ainda no cenário brasileiro, por volta de 1970, alguns nomes são relevados com publicações importantes, culminando com Medicina do trabalho e infortunística de Marigildo Camargo Braga e colaboradores. E em 1980, torna-se referência básica da área o livro do médico e professor René Mendes: Medicina do trabalho e doenças profissionais.

Campos (2006) informa que no Brasil, a partir da década de 1980, já começaram a aparecer alguns estudos tratando do tema do adoecimento de servidores públicos. Mendes e Dias (1991) também asseguram que nessa época a emergência da saúde do trabalhador passou a ser identificada no contexto de uma transição democrática sintonizada com o que ocorria no mundo ocidental.

Em 1978, o Ministério do Trabalho condensou as normas de segurança e proteção do trabalhador na Portaria $n^{\circ} 3.214 / 78^{8}$ que conta atualmente com 33 Normas Regulamentadoras - NR. A Constituição Federal de 1988 consagrou a saúde como direito social, assegurando 
9

Cf: $<$ http://bvsms.saude. gov.br/bvs/saudelegis/ gm/1999/prt1339_18_11_1999. $\mathrm{html}>$. Acesso em 15 de junho de 2015.

10

Cf: $<$ http://portalsaude. saude.gov.br/>. Acesso em 15 de junho de 2015 .

11

Cf: <http://www.planalto. gov.br/ccivil_03/decreto/ d3048.htm>. Acesso em 15 de junho de 2015. aos trabalhadores o direito à redução dos riscos inerentes ao trabalho por meio de normas de saúde, higiene e segurança - artigo $7^{\circ}$, inciso XXII. E a legislação previdenciária, assim como diversas leis ordinárias, em sintonia, do mesmo modo estabeleceu normas de proteção à saúde do trabalhador.

Apesar da homologação de diversas leis, Durand (2001) registra a lentidão no processo de reconhecimento das doenças ligadas ao trabalho, no Brasil, e lembra, por exemplo, que a LER (lesão por esforços repetitivos) só foi reconhecida como doença ocupacional em 1987. Saliente-se, porém, que os estudos sobre doenças psíquicas dos trabalhadores, propriamente dito, começaram a surgir desde o século passado. Anterior a esse momento a preocupação geral estava voltada para atender os interesses econômicos dominantes, o que significava estimular o desenvolvimento de estudos objetivando apenas o aumento da eficiência e eficácia da produção industrial e de controle ou extermínio de fatores que impedissem a produção e o lucro (sILva et. al., 1994).

No universo acadêmico, a partir da década de 70, desabrochou na literatura especializada um conjunto de investigações sobre a saúde do trabalhador que assinalava o caráter histórico e social do elemento saúde-doença. Os estudos se expandiram das patologias para o processo saúde-doença; já não se tratava de mero fenômeno biológico individual, mas biopsicossocial (silva et.al., 1994). Foi então nesse contexto que surgiu a Psicopatologia do Trabalho com produção de conhecimento e análise sobre a saúde psíquica do trabalhador.

Importa enunciar que as primeiras investigações sobre patologia mental no trabalho estavam direcionadas aos casos de trabalho repetitivo, sob pressão de tempo, às manobras na construção civil e aos servidores públicos franceses e imigrantes explorados, como lembra Dejours (1994).

Mostra-se necessário narrar que no Brasil, em 1999, aconteceu a promulgação da Portaria n⿳0 1.339/99 (MINISTÉRIO DA SAÚDE ${ }^{10}$, 1999) que apresenta os princípios norteadores utilizados para o diagnóstico das doenças relacionadas ao trabalho e dedica um capítulo aos chamados "transtornos mentais e do comportamento relacionados ao trabalho". E, sobretudo, que também em 1999, foi lançado o Segundo Manual do Ministério da Saúde (2001) que usa como referência essa Portaria e o Decreto $\mathrm{n}^{\mathrm{0}}$ 3.048/99 ${ }^{11}$ com suas alterações, e defende que o estabelecimento do nexo causal entre a doença e a atividade atual ou pregressa do trabalhador representa o ponto central para o correto diagnóstico e tratamento da doença.

\section{PSICOPATOLOGIA E PSICODINÂMICA DO TRABALHO}

De acordo com a recomendação de Seligmann Silva (1994), para estudar a relação entre saúde mental e trabalho é indispensável explorar o conteúdo produzido pela escola de Psicologia do Trabalho. Nos anos 50 as pesquisas da área, realizadas através de entrevistas individuais, se dedicavam ao estudo das perturbações psíquicas geradas 
pelo trabalho (DEJOURs, 1996). Nos anos 70 começou a surgir uma demanda social sobre estudos das condições psicológicas do trabalho e suas consequências para a saúde, a princípio, entre os trabalhadores semiqualificados, como declara Dejours (1994).

Inicialmente as pesquisas em Psicopatologia do Trabalho, como relata Dejours, destacavam um rol de afecções mentais que poderiam ser geradas pelo trabalho, ou seja, a patologia profissional somática vinda de danos físico-químico-biológicos provenientes do posto de trabalho. Até que os estudos famosos de Le Guillant e colaboradores trouxeram à tona síndromes que atingiam a saúde mental de profissões específicas, como faxineiras, telefonistas e mecanógrafos (DEJOURS, 1994).

Na proposta de uma abordagem mais renovada, Dejours (1994) admite que o trabalho não deveria ser limitado às "condições de trabalho", cujo estudo é o objeto escolhido pela ergonomia. Havia de se considerar a dimensão organizacional, ou seja, a divisão de tarefas e as relações de produção. Para o autor, essa postura significava assimilar aquilo que especifica o trabalho como "relação social", e fazer disso um caminho para articular um modelo de funcionamento psíquico que encontrasse um lugar teórico específico para a intersecção singular-coletivo.

Diversos estudos e pesquisas promoveram o amadurecimento da Psicopatologia do Trabalho e propôs assim uma nova disciplina: a Psicodinâmica do Trabalho. Seligmann Silva (1994), traduzindo as colaborações de Dejours, explica que o objeto dessa disciplina é justamente a análise psicodinâmica das situações de trabalho, ou seja, o estudo dos movimentos psicoafetivos gerados pela evolução dos conflitos inter e intrasubjetivos, contudo, limitados ao espaço do trabalho.

No que concerne ao itinerário histórico da Psicodinâmica do Trabalho (PDT), ele foi de fato iniciado na França, na década de 1980, e pode ser dividido em três momentos. O primeiro momento enfocava questões relacionadas ao sofrimento vivenciado pelos trabalhadores e as estratégias de defesa utilizadas para o enfrentamento dessas vivências; o segundo, que se estendeu até metade da década de 1990, enfatizava o prazer e ensaiava uma análise mais profunda das estratégias de defesa, utilizadas como forma de alcançar maior prazer no trabalho; o terceiro momento permanece até os dias atuais e estuda a construção da identidade social do trabalhador, tendo o trabalho como fonte dessa construção.

Foi a partir do começo dos anos 80, que a PDT mostrou maior cuidado em fundamentar a clínica do sofrimento na relação psíquica com o trabalho, já que "a investigação clínica tradicional centrava a análise mais nas doenças do que nos mecanismos subjacentes à normalidade sofredora" (DEJOURS, 1996, p. 153).

O interesse central da PDT, como explica Dejours (1998), é direcionado justamente para os conflitos surgidos da conexão estabelecida entre o trabalhador, portador de história singular e preexistente, e 
uma situação de trabalho com características específicas e por vezes contraditórias às vontades do sujeito.

A priori, um esclarecimento que precisa ser feito, segundo o autor, diz respeito à adoção do termo 'psicopatologia' para designar interações que nem sempre resultam em patologia propriamente dita. O termo em referência traz em sua raiz a palavra pathos, que remete ao sofrimento e não só a doença ou à loucura, e por isso, interessa profundamente a esta pesquisa. Como o próprio Dejours coloca, e aqui se ratifica, "ao longo do texto, como em toda literatura publicada depois do final dos anos 70 (...), o termo psicopatologia não será, portanto, jamais compreendido no sentido restritivo do mórbido" (DEJOURS, 1994, p. 120).

O autor esclarece que "a organização do trabalho exerce, sobre o homem, uma ação específica, cujo impacto é o aparelho psíquico" (DEJOURs, 1998, p. 133). Observe-se, porém, que com esta sustentação, ele não atribui às instituições a culpa do sofrimento do indivíduo. Ainda que a organização do trabalho possa explorar ou estimular certo sofrimento mental, não se originam aí as doenças mentais. Existe o sofrimento singular, herança da história psíquica própria de cada ser, o que denomina de dimensão diacrônica, e o sofrimento atual, que aparece no reencontro com a situação do trabalho e se trata da dimensão sincrônica (DEJours, 1996).

O novo fôlego atingido pela Psicopatologia do Trabalho surge, conforme Dejours (1996), exatamente quando admitindo a normalidade dos trabalhadores em situação de trabalho se começa a enxergá-la como um enigma. A sua grande questão era compreender como os trabalhadores, em sua maioria, conseguiam, apesar das situações constrangedoras ou anormais no trabalho, manter certo equilíbrio e certa normalidade. Entendia Dejours que "a normalidade dos comportamentos não implica a ausência de sofrimento. E que o sofrimento, além disso, não exclui o prazer" (DEJOURS, 1994, p. 47).

\section{CONSIDERAÇÕES SOBRE O SOFRIMENTO PSÍQUICO DO TRABALHADOR}

Na Psicodinâmica do Trabalho, Dejours (1994) reforça que seu objeto de estudo é o sofrimento no trabalho. E ainda determina que esse sofrimento é compatível com a normalidade e com a salvaguarda do equilíbrio psíquico. Desse modo, concebe o sofrimento como "vivência subjetiva intermediária entre a doença mental descompensada e o conforto (ou bem-estar) psíquico. Se a doença mental é fácil de definir, o bem-estar ou boa saúde mental é mais difícil de compreender" (DEJOURS, 1994, p. 127).

Souza (1992) afirma que o trabalho, quando executado sob determinadas condições, pode causar doenças, encurtar o tempo de vida ou até mesmo matar os trabalhadores. Garante que a identificação do nexo causal entre trabalho e sofrimento psíquico é antiga. Alega, no entanto, que está sendo construída recentemente a concepção de que o trabalho pode provocar corrosão da saúde e das subjetividades dos trabalhadores de uma maneira sutil e mesmo invisível. 
Na direção contrária, porém, Borsoi (2007) assevera que durante muito tempo as principais explicações para o surgimento do sofrimento psíquico do homem foram a herança genética, os aspectos orgânicos e a história familiar e afetiva dos indivíduos. $\mathrm{O}$ trabalho não era encarado como fator significativo a ponto de merecer ser visto também como um aspecto preponderante na constituição desse tipo de sofrimento.

Em suas elucidações, Dejours (1992) faz questão de estabelecer uma diferenciação entre a organização do trabalho e as condições de trabalho. É mister que não se faça uma limitação às pressões físicas, químicas, biológicas ou mesmo psicossensoriais do posto de trabalho, geralmente denominadas 'condições de trabalho'. E explica que "as relações entre sofrimento e organização não caminham sempre no sentido do sofrimento, já que o trabalho também pode ser fonte de prazer, e mesmo mediador da saúde" (DEJOURS, 2012, p. 150).

Dejours (1996) admite ainda que para enfrentar o sofrimento desencadeado pela inadequação da pessoa à organização do trabalho são utilizados pelos trabalhadores mecanismos de defesa em sua maioria de forma coletiva, buscando assim atenuar as vivências de sofrimento e aumentar as de prazer, para que se torne suportável a permanência dentro das organizações. Sobre o aspecto da normalidade do trabalhador, o teórico afirma que o termo não traz a ideia de status ideal. Pelo contrário, a normalidade dos trabalhadores é apresentada de modo artificial, pois é alcançada e mantida pela força e pela luta constante e, por isso, perpassada constantemente pelo sofrimento. "A normalidade é um indício da guerra contra a doença mental", assegura ele (DEJOURs, 1996, p. 153).

Aprofundando mais o tema, Dejours (1994) indica que o sofrimento implica um estado de luta do indivíduo contra as forças que o direcionam à doença mental. E expõe que, quando na batalha contra o sofrimento psíquico, o sujeito consegue criar soluções autênticas e capazes de beneficiar tanto a produção quanto à sua saúde, ele produz um sofrimento criativo. Por outro lado, quando o sujeito não alcança essas condições benéficas para a produção e para sua saúde, padece de sofrimento patogênico (DEJOURS, 1996).

Para Gaulejac, o que trabalhador precisa é dar valor ao que executa, encontrar significado nisso e ter liberdade para criar e se expressar dentro do seu trabalho para sentir-se confortável e saudável. Mendes e Tamayo (2001) estão de acordo com essas ideias e concebem que o trabalho pode de fato ser gerador de sofrimento e, que este começa quando o trabalhador não consegue se identificar com aquelas atividades que realiza; quando não estabelece uma integração entre as suas realidades psíquicas e aquelas impostas pela organização e divisão do trabalho.

Na compreensão de Dejours (1992), quando o trabalhador descobre a impossibilidade de utilizar suas habilidades, sua capacidade criativa, ou mesmo de se expandir profissionalmente, vê-se no processo de automatismo e artificialidade para realizar seu trabalho. Isso é 
apresentado pelo autor como o bloqueio da relação entre a pessoa e a organização e, faz com que o trabalhador sinta-se desgastado.

\section{GESTÃO E ORGANIZAÇÃO DO TRABALHO X SOFRIMENTO PSÍQUICO DO SERVIDOR}

Mendes (1995) assegura que a organização tende a ser a esfera mais determinante dos agravos psíquicos relacionados ao trabalho. Adverte sobre a necessidade de serem levados em conta os tipos de gestão e a qualidade das relações humanas no trabalho. Dessa maneira, põe em destaque uma questão bem importante: a leitura das expressões invisíveis e dos distúrbios psíquicos disfarçados pelo trabalhador, que se manifestam frequentemente, segundo ele, por incidentes ou acidentes de trabalho, falhas de desempenho, faltas, conflitos interpessoais, acidentes de trajeto, conflitos familiares e envolvimento em conflitos extratrabalho.

No âmbito geral, Gaulejac (2006) inova conceitos quando se refere à gestão como uma doença social no sentido de provocar pressão e desarmonia no indivíduo a ela submetido. Ao se levar em consideração o papel da gestão dentro de uma empresa, relaciona-se a isso a função de organizar o ambiente para atuar e produzir com sucesso, e inclui-se no pacote a função de administrar pessoas, ou seja, relações humanas.

No âmbito do serviço público Campos enxerga uma degradação na administração e exemplifica:

fenômenos como doenças ocupacionais, absenteísmo, assédio moral, dentre as principais patologias do sistema organizacional, refletem o modo degradado de funcionamento da administração pública, assim como a interferência dos processos sociais e políticos na organização e no desenho do trabalho (CAMPOS, 2006, p. 16).

Quando aborda a questão da mudança na administração pública do paradigma burocrático para o gerencial, Siqueira e Mendes (2009) destacam a necessidade de verificar o que de fato faz sentido para o setor público adotar do privado nesse processo de importação, haja vista as peculiaridades da gestão pública. E o ponto que mais merece atenção, na concepção desses autores, é justamente o servidor público que vai receber em sua subjetividade a maior parte do impacto dessa transformação, já que essa ideologia gerencial e a nova forma de pressão podem repercutir nas relações de trabalho.

Gaulejac enxerga certa insensatez na modernização do serviço público justamente por reconhecer que esse detém uma lógica diferente e peculiar. Para ele, "a modernização resulta em uma financeirização crescente das atividades, no desdobramento das ações das carreiras e das competências. Qualidade, eficácia, rentabilidade, o serviço público integra valores novos". (GAULEJAC, 2014, p. 158). Esse panorama confunde o agente público no que diz respeito à direção que deve tomar e se torna "um exemplo dos efeitos de nonsense do contrassenso produzido 


\section{2}

Cf: <http://www.planalto. gov.br/ccivil_03/decreto/ di171.htm>. Acesso em o5 de julho de 2015. pela importação da lógica comercial nos meios de trabalho impregnados por uma cultura do serviço público" (GAULEJAC, 2014, p. 159).

Siqueira e Mendes se reportam a um processo contínuo onde modelos e modismos gerenciais são insistentemente "implantados na expectativa de que a estrutura governamental possa atender de modo mais eficiente e eficaz às demandas sociais" (SIQUEIRA e MENDES, 2009, p. 241). Entretanto, esses autores julgam que mesmo que a gestão deva estar direcionada para resultados, precisa estar atenta para, em nome disso, não destruir as relações de trabalho. Conquanto, não haja a intenção de rejeitar a necessidade de maior eficiência e eficácia na administração pública eles alertam para o perigo dos efeitos que podem advir da obsessão por produtividade e por resultados.

Gaulejac (2014) também acredita que o modelo gerencialista está voltado mais às tarefas do que às pessoas, o que precariza o trabalho e desmotiva o servidor e faz, ainda, com que o indivíduo encontre pouco espaço para diálogo e exercício da criatividade durante a execução das tarefas. E se, como acredita Bellusci (2003), as alterações advindas da organização do trabalho e suas condições de higiene e segurança, geradoras de conflito entre prazer e sofrimento, podem ser utilizadas pela empresa para aumentar a produtividade, essa fórmula necessariamente não funciona no espaço do serviço público, já que nele o aspecto da produtividade é tratado de modo bem particular (BELLUSCI, 2003, p. 16).

O Código de Ética do Servidor Público Civil do Poder Executivo Federal ${ }^{12}$, criado em 1994, através do Decreto $\mathrm{n}^{\mathrm{0}}$ 1171, no inciso V do Capítulo I, supõe ainda assim que o servidor deve, no exercício do trabalho, contribuir para seu próprio bem-estar e da sociedade, admitindo que "o trabalho desenvolvido pelo servidor público perante a comunidade deve ser entendido como acréscimo ao seu próprio bem-estar, já que, como cidadão, integrante da sociedade, o êxito desse trabalho pode ser considerado como seu maior patrimônio".

Lancman et.al., refletem que apesar de vivenciarem relações menos instáveis de trabalho, os profissionais do setor público estão expostos a outras formas de fragilidade e precarização do trabalho, tais como: privatização de empresas públicas seguidas de demissões, terceirização de setores dentro da instituição, deterioração das condições de trabalho e da imagem do trabalhador do serviço público, e responsabilização deles pelas deficiências dos serviços e por possíveis crises das instituições públicas etc (LANCMAN et.al., 2007).

Concordando com isso, Nunes e Lins (2009) apontam que a instabilidade devido a mudanças políticas, as ações descontinuadas, o acúmulo de funções, além do estereótipo da morosidade, são aspectos reais que podem afetar a saúde do servidor. Além disso, frisam que mesmo dispondo de certa estabilidade, o servidor público está sujeito a situações de adoecimento e de sofrimento similares ao funcionário de empresa privada no que toca às condições e à organização de trabalho própria de cada instituição. 
Já na opinião de Morrone et.al. (2004), o processo de adoecimento incapacitante entre servidores públicos está diretamente relacionado com a falta de flexibilidade organizacional no sistema público. Gaulejac (2014) observa que

quando os dispositivos de avaliação e de reconhecimento estão desligados dos valores e do sentido que os agentes públicos atribuem a sua atividade, entramos numa crise de simbolização. E nesse quadro, o servidor também pode desenvolver a insatisfação e o sofrimento (GAULEJAC, 2014, p. 158).

Exemplificando as fragilidades presentes no contexto específico do ambiente do serviço público e a relação entre saúde mental, trabalho e adoecimento, Pires e Macêdo relatam que

(...) as organizações públicas mantêm as mesmas características básicas das demais organizações, acrescidas, entretanto, de algumas especificidades como: apego às regras e rotinas, supervalorização da hierarquia, paternalismo nas relações, apego ao poder, entre outras (PIRES e MACÊDO, 2006, p. 96).

\section{METODOLOGIA DE PESQUISA}

Em função do objeto estudado, a abordagem metodológica escolhida para esta pesquisa seguiu o caminho do método qualitativo. A pesquisa qualitativa pode ser encarada, segundo a concepção de Richardson, como "a tentativa de uma compreensão detalhada dos significados e características situacionais apresentadas pelos entrevistados, em lugar da produção de medidas quantitativas de características ou comportamentos" (RICHARDSON, 2009, p. 90).

No que se refere aos fins, esta pesquisa pode ser considerada exploratória, porque pretende proporcionar maior familiaridade com o problema estudado para torná-lo mais explícito. No que concerne aos meios, coloca-se como uma pesquisa bibliográfica, documental e de campo (GIL, 2005). Bibliográfica, porque desenvolve um estudo teórico sobre a relação entre sofrimento e trabalho. Documental, uma vez que foram utilizados registros e relatórios fornecidos pela UFPE com informações institucionais a respeito do objeto de estudo. E pesquisa de campo, pois foram efetuadas entrevistas semiestruturadas com servidores da referida universidade (Op. cit., 2005).

O lócus definido para este trabalho foi a Universidade Federal de Pernambuco, especificamente o campus Recife, tendo sido ponderado ainda o fato de que essa unidade representa a maior parte do corpo da Universidade, além de abrigar os órgãos que coordenam as atribuições administrativas e jurídicas da instituição: Reitoria, Pró-reitorias e Procuradoria Geral.

Não se vislumbrou outro caminho que não o de entrevistar os próprios servidores da UFPE acerca do tema central deste estudo por 
considerar essencial a sugestão de Dejours (1982), segundo o qual, em se tratando da matéria de saúde, de condições do trabalho e de organização do trabalho, tudo deve ser inspirado pelos próprios trabalhadores, incluindo a direção a ser dada a essa contribuição.

Os servidores entrevistados nesta pesquisa exercem cargo de técnico administrativos em educação (TAE) na Universidade e que abarca as escolaridades de nível fundamental, médio, médio profissionalizante e superior, conforme rege a Lei $\mathrm{n}^{\mathrm{o}} 11.091 / 2005$, que dispõe sobre a estruturação do Plano de Carreira dos Cargos Técnico-Administrativos em Educação, no âmbito das Instituições Federais de Ensino vinculadas ao Ministério da Educação.

Para realização das entrevistas, foram convidados, de forma aleatória, servidores técnico-administrativos que se mostraram disponíveis durante as visitas realizadas, no período de maio a agosto de 2016 , em diversas unidades da instituição, a saber: Hospital das Clínicas - HC, Reitoria e centros acadêmicos: Centro de Artes e Comunicação - CAC; Centro de Biociências - $\mathrm{CB}$; Centro de Ciências Exatas e da Natureza - ccen; Centro de Ciências Jurídicas - CCJ; Centro de Ciências de Saúde - cCs; Centro de Ciências Sociais e Aplicadas - cCSA; Centro de Educação - CE; Centro de Filosofia e Ciências Humanas - $\mathrm{CFCH}$; Centro de Informática - cin e Centro de Tecnologia e Geociências - CTG, totalizando o total de 12 (doze) entrevistas.

Houve o cuidado de entrevistar servidores de gêneros, idades, cargos e tempos de serviço variados com o intuito de trabalhar com maior diversidade e representatividade de opiniões e experiências possíveis. A idade dos entrevistados variou entre 31 e 68 anos. O tempo de serviço variou de 02 a 37 anos. Os cargos dos entrevistados foram: Administrador de Edifício, Auxiliar em Administração, Assistente em Administração, Enfermeira, Secretária Executiva e Técnico em Assuntos Educacionais.

O instrumento utilizado para a coleta de dados deste trabalho foi a entrevista. Ao tratar das formas mais recorrentes de entrevista nas Ciências Sociais, Boni e Quaresma (2005) anunciam a existência dos seguintes tipos: estruturada, semiestruturada, aberta, com grupos focais, história de vida e projetiva. No caso deste estudo, a opção pela entrevista do tipo semiestruturada ocorreu por considerá-la a maneira mais apropriada de extrair informações sobre a vida pessoal e profissional dos servidores.

As questões que compuseram a entrevista foram elaboradas com o intuito de articular os pressupostos teóricos usados neste estudo, buscando extrair a realidade, na percepção dos servidores, sobre vivências de ordem pessoal e profissional para poder sistematizar categorias de análise adequadas aos objetivos propostos. De acordo com Bauer e Gaskell (2002), a compreensão dos mundos da vida dos entrevistados é condição obrigatória na entrevista qualitativa.

Para a condução da entrevista - etapa da pesquisa de campo foi elaborado um roteiro com 18 perguntas que abordavam algumas 
questões da vida particular, mas que focaram principalmente na vida profissional dos servidores. Esse roteiro foi organizado a partir de tópicos centrais amplos que davam espaço para complementações com novas perguntas de acordo com a necessidade observada pelo pesquisador.

Inicialmente o pesquisador registrava dados socioeconômicos: gênero, idade, setor de trabalho, escolaridade, tempo de serviço na instituição e cargo ou função desempenhada pelo entrevistado. Em seguida, era solicitado que o entrevistado fizesse um relato resumido, de maneira livre, do que considerava importante na sua história de vida pessoal e, depois, um resumo, também de modo espontâneo, do que considerava relevante no seu histórico profissional. Havendo necessidade, logo após o resumo o entrevistador perguntava sobre outros aspectos da vida do servidor considerados importantes para a pesquisa e que não haviam sido indicados em sua fala. Exemplo disso seria a omissão de informações sobre os pais no resumo da vida pessoal e a omissão do trabalho na UFPE no resumo da vida profissional.

\section{APRESENTAÇÃO E ANÁLISE DOS DADOS}

Tomando por base o objetivo desta pesquisa e recuperando as referências teóricas aqui trabalhadas, o caminho de análise contemplou os processos de: capturar os registros do sofrimento na vida pessoal e profissional dos servidores; verificar se estes sofrimentos se relacionam entre si; constatar a influência da organização do trabalho no sofrimento dos servidores; perceber se os servidores usam estratégias de defesa contra o sofrimento; investigar se os servidores adoecem por causa do trabalho e por fim, se os servidores têm ciência de casos de adoecimento mental por trabalho na UFPE.

\section{CATEGORIAS DE ANÁLISE}

As categorias de análise foram formuladas com base na teoria apresentada por Dejours. Aqui foram analisadas as falas dos entrevistados que se encaixam com cada uma das categorias formuladas para verificar se as teorias trazidas na Psicodinâmica do Trabalho, podem ser confirmadas na realidade do trabalho dos servidores técnicos administrativos em educação da UFPE. Todas as entrevistas foram utilizadas na análise.

Antes de apresentar a análise propriamente dita é bom mencionar as categorias analisadas:

1. Sofrimento na vida pessoal

2. Sofrimento no trabalho

3. Relação entre sofrimento na vida pessoal e o sofrimento no trabalho

4. Relação entre o sofrimento e a organização do trabalho

5. Relação entre adoecimento e trabalho

6. Estratégias de defesa

7. Percepção sobre servidores doentes 
Esta categoria de análise teve por intenção captar algumas passagens da história de vida pessoal dos servidores para tentar identificar a existência do sofrimento, e mais à frente, compreender se isso influencia no seu trabalho.

Quando solicitado aos servidores que fosse feito um resumo das suas histórias de vida pessoal com tudo o que considerassem importante, percebeu-se que a maioria dos entrevistados demonstrou a tendência em construir um resumo com apenas duas ou três frases e imediatamente começar a falar da vida profissional. Isso talvez possa denotar que o trabalho possui um papel marcante na vida desses sujeitos.

Quatro entrevistados, ao relatarem suas vivências, garantiram que não reconheciam nenhum sofrimento marcante em suas histórias de vida. Alguns deles, inclusive, destacaram que tiveram uma vida muito tranquila e equilibrada com seus pais e irmãos. Apesar dos discursos de alguns servidores que aparentemente demonstraram não terem vivenciado o sofrimento em suas histórias pessoais e não apresentaram dificuldades de lidar com o sofrimento no trabalho, Dejours (1994) garante que a normalidade dos comportamentos não significa a ausência de sofrimento. E ainda assegura que sentir o sofrimento não exclui a possibilidade de sentir prazer.

Cabe reforçar que embora Dejours (1994) tenha garantido que todo indivíduo possui sofrimento na sua história de vida particular, nesta pesquisa foram aceitas as opiniões e percepções trazidas pelos servidores entrevistados, mesmo que contrariassem o pensamento do teórico principal deste estudo. Sobretudo, foi respeitada a subjetividade de cada um, já que o próprio autor vai falar sobre essa questão, e mais adiante, ela também será abordada numa outra categoria de análise.

Tomando por base essas premissas, pode-se concluir que dos doze servidores entrevistados, quatro não reconhecem o sofrimento em sua história particular de vida e oito perceberam e reconheceram alguma vivência significativa de sofrimento.

\section{SOFRIMENTO NO TRABALHO}

Quando solicitado aos servidores que fizessem um resumo da sua vida profissional contemplando tudo aquilo que considerassem preponderante, notou-se que nenhum deles encontrou dificuldade para construir o relato. Inclusive, alguns dos entrevistados começaram a discorrer sobre os acontecimentos profissionais desde a época de estágio.

Estabeleceu-se a presente categoria de análise para recolher informações acerca das experiências dos servidores e saber se esses reconhecem a presença do sofrimento no trabalho.

Constatou-se que diversos entrevistados historiaram, com certo incômodo, a existência de determinados aspectos do sofrimento no trabalho, tais como: acomodação de outros colegas, resistência de alguns servidores ao novo, visões diferentes interferindo nas relações inter- 
pessoais, problemas com hierarquia e omissão por parte dos colegas e em alguns casos, por parte das chefias, com quem trabalham.

Conclui-se que todos os servidores entrevistados reconhecem alguma forma de sofrimento no trabalho. Alguns relataram fatos passados e outros garantiram estar vivendo o sofrimento na atualidade. Reporte-se, porém, que alguns entrevistados aparentaram lidar de forma tranquila com o sofrimento.

\section{RELAÇÃO ENTRE SOFRIMENTO NA VIDA PESSOAL E SOFRIMENTO NO TRABALHO}

Como afiança Dejours (1996) existe uma relação entre o sofrimento singular, herança da história psíquica do indivíduo (dimensão diacrônica) e o sofrimento atual, que é ativado por uma situação do trabalho (dimensão sincrônica). Baseada nesta premissa, esta categoria de análise tentou verificar a possibilidade de situar no discurso dos entrevistados um fator que pudesse apontar para existência da ligação proposta por Dejours.

Nesta categoria foi possível enxergar que metade dos entrevistados possui situações de sofrimento no trabalho que apontam para a existência de um sofrimento originado em suas histórias de vida.

\section{RELAÇÃO ENTRE SOFRIMENTO E ORGANIZAÇÃO DO TRABALHO}

Objetivou-se com essa categoria de análise coletar as percepções e experiências dos servidores e investigar se nas vivências de sofrimento no trabalho existia a influência específica do elemento organização de trabalho.

Indagado aos entrevistados sobre circunstâncias existentes no trabalho suscetíveis de causar-lhes sofrimento, todos eles, sem exceção, citaram aspectos ligados ao elemento organização do trabalho, confirmando a ideia de Dejours (1994).

Vários entrevistados se queixaram de servidores, companheiros de trabalho, que são acomodados e desinteressados. É provável que isso demonstre uma falha da chefia em administrar seus colaboradores. Por fim, é válido confirmar que todos os entrevistados enunciaram algum elemento da organização do trabalho como sendo o estimulador do desenvolvimento do sofrimento. Apenas três servidores além de enunciarem sofrimento ligado a este elemento, também se queixaram de aspectos ligados às condições de trabalho, inclusive, citando coisas como móveis inadequados para execução das tarefas.

\section{RELAÇÃO ENTRE ADOECIMENTO E TRABALHO}

Esta categoria de análise teve como objetivo investigar se os servidores estão conseguindo vencer a guerra contra o adoecimento mental abordada por Dejours ou se chegam ao ponto de adoecer psiquicamente. Lembrando que para o autor, o sofrimento é compatível com a normalidade e com a salvaguarda do equilíbrio psíquico. 
Dentre os doze entrevistados, apenas quatro admitiram que chegaram a adoecer por motivos relacionados ao sofrimento no trabalho. Dois desses servidores ainda hoje estão em tratamento psicológico em razão do sofrimento. $\mathrm{O}$ terceiro, ainda apresenta o problema desenvolvido, mas não faz acompanhamento psicológico, apenas trata o sintoma físico da doença, que segundo informa, não tem cura. A quarta entrevistada comentou sobre várias doenças (no corpo físico) que já teve e foram ligadas à questão de estresse no trabalho, mas confessou que chegou a rasgar atestado médico para continuar trabalhando.

\section{ESTRATÉGIAS DE DEFESA}

Para Dejours (1996), os trabalhadores geralmente costumam construir o que ele chama de defesas coletivas e de ideologias defensivas da profissão. No caso do presente estudo, só foram observadas estratégias individuais de defesa. Não houve nenhuma menção ao uso de estratégia coletiva por parte de nenhum dos servidores.

Nesta categoria apenas dois servidores não conseguiram demonstrar a elaboração de estratégia de defesa contra o sofrimento no trabalho. Recorde-se que no entendimento de Dejours (1994), a normalidade dos comportamentos não significa necessariamente a ausência de sofrimento. $\mathrm{O}$ servidor pode desempenhar suas atividades dentro de um padrão aceito e nutrir, no silêncio, o sofrimento.

\section{PERCEPÇÃO SOBRE SERVIDORES DOENTES}

A intenção de acrescentar essa pergunta ao roteiro de entrevista foi uma tentativa de aumentar o campo de alcance para enxergar alguma ocorrência que pudesse significar doença (por causa do trabalho) ao redor dos que já estavam sendo entrevistados.

Quando perguntado aos colaboradores se tinham conhecimento de algum servidor que houvesse se afastado de suas atividades por apresentar algum tipo doença psíquica, a maioria respondeu que sim. Apenas dois entrevistados responderam negando conhecimento sobre casos com este. No entanto, um deles descreveu que havia encontrado casos desse gênero apenas no seu antigo local de trabalho dentro da Universidade.

Ademais, outros servidores limitaram-se a responder essa pergunta apenas afirmando ou negando, mas sem interesse de relatar situações ou exemplos, o que foi respeitado pelo pesquisador.

\section{ANÁLISE DOCUMENTAL}

Após o estudo das informações fornecidas pelo NAss e pelo DGP foram feitas algumas análise dos dados selecionados dos documentos e relatórios da Universidade que dizem respeito às faltas injustificadas e às licenças para tratamento de saúde (LTS) com foco no CID F, dos servidores técnicos administrativos em educação, no período de 2011 a 2015. 
Verificou-se que em 2015 a UfPE contabilizou o total de 1.025 (mil e vinte e cinco) faltas injustificadas cometidas por técnicos administrativos em educação. Em 2014, o número alcançou a marca de 1.553 (mil quinhentas e cinquenta e três) faltas. Já em 2013 o número de faltas foi de 2.784 (duas mil setecentos e oitenta e quatro). No ano de 2012, foram computadas 2.025 (duas mil e vinte e cinco) ocorrências e em 2011, o número chegou a 2.030 (duas mil e trinta).

No que diz respeito ao absenteísmo dos servidores motivados por doença, registre-se que em 2015 a UFPE contabilizou o total de 1.972 (mil novecentas e sessenta e duas) licenças, distribuídas em 22 cids. Dessas ocorrências, o grupo que interessa a esta pesquisa é o CID F (transtornos mentais e comportamentais), e este atingiu a marca de 247 (duzentas e quarenta e sete) licenças concedidas por perícia médica no ano de 2015 e mais 1 (uma) licença concedida por registro de atestado. Assim, em 2015 foram contabilizadas um total de 248 (duzentas e quarenta e oito) licenças do CID F. Destaque-se que as ocorrências mais frequentes nesse CID dizem respeito a doenças relacionadas aos sintomas de depressão. O relatório das licenças de CID F está disponível no Anexo I desta pesquisa.

Já as licenças do CID F concedidas por perícia médica no ano de 2014 foram 215 (duzentas e quinze) com mais 13 licenças concedidas por registro de atestado, o que contabiliza um total de 228 licenças. Acrescente-se que foram contabilizadas também 247 (duzentas e quarenta e sete) licenças do CID F em 2013 e mais 11 (onze) licenças por atestado validado. Já no ano de 2012 observou-se a ocorrência de 219 (duzentas e dezenove) casos de licenças e mais o6 (seis) por validação de atestado, e em 2011 foram registrados no sistema apenas 81 (oitenta e uma) licenças e mais 02 (duas) por atestado registrado e validado.

Os números apresentados de afastamentos por LTs ligadas ao CID F, referentes ao período de 5 (cinco) anos, não abriga em seu corpo a realidade em que o servidor, mesmo doente, não apresenta atestado médico ao NAss, como alguns entrevistados confessaram. Nesses casos, o servidor apenas opta por, quem sabe, cometer a falta injustificada, entrando na estatística citada anteriormente ou continuar trabalhando mesmo com condições limitadas, prejudicando o desempenho de suas funções, sua própria saúde e por consequência, a instituição.

\section{CONSIDERAÇÕES FINAIS}

Os frutos advindos desta pesquisa tratam do que poderá ser oferecido à Universidade através de conhecimentos e informações sistematizadas aqui e de sugestões que surgiram naturalmente dos diálogos estabelecidos com os servidores. Houve uma intenção de despertar o olhar da UFPE para o sentimento e a percepção dos servidores no que diz respeito à relação entre a gestão e o sofrimento, sobretudo, ao modo como a instituição administra e se relaciona com seus recursos humanos.

Após a análise dos relatos das experiências pessoais e profissionais dos entrevistados, foi possível identificar que em cada um deles 
existe algum sofrimento, ou pelo menos algum incômodo, incentivado pelo seu trabalho na UFPE. E mais ainda, foi fácil encontrar aspectos relacionados à organização do trabalho como fonte ou estímulo desse processo. Entretanto, não se pode afirmar que o sofrimento da história de vida pessoal dos servidores da UfPE se relacione com o sofrimento por eles vivenciado no âmbito profissional, lembrando ainda que nem todos os entrevistados reconheceram sofrimento em suas histórias pessoais.

De um modo geral, a herança da história de vida particular dos entrevistados pareceu ter uma forte influência sobre o modo como cada um se relaciona com o trabalho, porém mesmo havendo registro de sofrimento confirmado pelos servidores em suas histórias pessoais, nem sempre o problema em questão foi reconhecido por eles numa relação com o trabalho.

Alguns incômodos sobre o trabalho na Universidade foram mencionados em diversos momentos e em depoimentos variados. É claro que a amostra analisada foi pequena em comparação ao universo da UFPE, mas essa tentativa foi feita para verificar se o recurso de escuta ativa seria capaz de fornecer dados que pudessem servir de análise para o problema escolhido nesta pesquisa. E de fato, esse instrumento provou-se eficaz. Portanto, conjectura-se que essa prática possa ser utilizada pela Universidade, por exemplo, para formular seu planejamento estratégico. Uma pesquisa aplicada em seus servidores talvez ajudasse a criar melhorias para a instituição.

E a sugestão aqui, depois de ouvir alguns deles, é que a UFPE se empenhe para compreender os motivos que levam esses sujeitos a adotarem tais comportamentos e, sobretudo, pensar numa maneira de trabalhar esses motivos para minimizar os prejuízos que a própria instituição tem em decorrência dessas posturas. A Universidade tem condições de mapear melhor esses motivos e realizar uma intervenção não individualizada para cada servidor, mas que alcance todas as possibilidades do adoecer e do faltar sem justificativas, incluindo aí as situações causadas por manifestações de diferentes tipos de sofrimento.

Um dos objetivos era o de identificar como o tema do sofrimento psíquico do servidor é abordado, compreendido e o que é feito nesse sentido no âmbito geral e na ufPE. Compreendeu-se que muito escapa ao olhar da UFPE nesse assunto. E mesmo quando acontece uma situação grave, como a de assédio moral, a impressão que fica é que o servidor precisa se autossocorrer e procurar por acolhimento da forma que considerar mais adequada. Dentre os sofrimentos, incômodos e problemas enumerados pelos servidores e relatados na seção de análise dos dados, há muitas situações repetidas. Isso pode revelar que certas ocorrências são mais comuns do que se imagina no universo dos servidores e que de fato não estão sendo enxergadas pela gestão.

Entretanto, constatou-se que apesar de todos os entrevistados terem muitas ressalvas e críticas em relação a vários aspectos da gestão da Universidade, o que poderia acontecer em qualquer instituição, a 
maioria registrou que gosta de trabalhar na ufPe. Alguns, inclusive, destacaram que sentem prazer, orgulho e alegria na atividade que executam ou por trabalhar na Universidade. Constatações como estas autenticam a ideia de que enquanto existe sofrimento, mas ainda há algum nível de prazer e satisfação em relação ao trabalho, é possível construir um equilíbrio "entre o pessoal e o profissional" antes que o aspecto negativo seja reforçado. No entanto, ao que tudo indica, os servidores demonstraram que gostariam de ser ouvidos e acolhidos pela gestão da Universidade.

Pensando numa forma de melhorar as condições atuais, apontadas como negativas pelos próprios servidores, no que concerne ao sofrimento e ao adoecimento mental, uma sugestão seria a criação de um programa multidisciplinar para lidar com esses problemas, o qual poderia ser coordenado pela PROGEPE e implementado pelo NASS, DQV e DGP - setores que efetivamente atendem e trabalham com as questões de saúde e qualidade de vida dos trabalhadores da UFPE. Estes setores poderiam unir esforços para encontrar uma maneira de estabelecer um mapeamento mais específico em relação ao sofrimento e ao adoecimento psíquico do servidor e, sobretudo, trabalhar preventivamente as situações que, nesse sentido, sinalizem perigo.

Finalmente o que se vislumbra é que não existe possibilidade de uma instituição oferecer permanentemente um serviço de qualidade à sociedade sem alimentar o interesse pela da saúde dos seus servidores, em todos os seus âmbitos, incluindo aí a saúde mental. Um trabalho saudável com resultados satisfatórios só acontece quando o servidor tem respeitada sua identidade, estimuladas as suas capacidades e compreendidas as suas limitações. É essa realidade que se espera ver na Universidade Federal de Pernambuco.

\section{REFERÊNCIAS BIBLIOGRÁFICAS}

BAUER, Martin W.; GASKELL, George. Pesquisa qualitativa com texto, imagem e som: um manual prático. $11^{\underline{a}}$ Ed. Petrópolis: Editora Vozes, 2002.

\section{BELLUSCI, Sílvia Meirelles. Doenças profissionais ou} do trabalho. São Paulo: SENAC, $5^{\underline{a}}$ edição, 2003.

BONI, Valdete. QUARESMA, Sílvia Jurema. Aprendendo a entrevistar: como fazer entrevistas em Ciências Sociais. Revista Eletrônica dos Pós-Graduandos em Sociologia Política da UFSC. Vol. 2 nº 1 (3), janeiro-julho/2005, p. 688o. Disponível em <abrhttps://periodicos.ufsc.br/index.php/ emtese/article/viewFile/18027/16976> acesso em 14 abr. 2016.

BORSOI, Izabel Cristina F. Da relação entre trabalho e saúde à relação entre trabalho e saúde mental. Revista Psicologia \& Sociedade, v. 19, 2007. Disponível em <http://www.scielo.br/scielo.php?script=sci_ arttext\&pid=So102-71822007000400014 $>$ acesso 21 mar. 2016. 
CAMPOS, F. E. de. A desprecarização é urgente. Radis Comunicação em Saúde, Rio de Janeiro, n.46, p.8-10, jun. 2006.

CANGUILHEM, Georges. O normal e o patológico.

São Paulo: Forense Universitária, 6 6 edição, 2009.

DEJOURS, Christophe et. al. Psicodinâmica do trabalho: contribuições da escola dejouriana à análise da relação prazer, sofrimento e trabalho. São Paulo: Atlas, 1994. 145p.

DEJOURS, Christophe. Note de travail sur la notion de souffrance. Dejours, C., éd., Plaisir et souffrance dans le travail, v. 1, p. 115123, 1987. Disponível em <http://cems.ehess.fr/docannexe/file/3363/ cottereau_plaisir_souffrance_justice_inj.pdf $>$ acesso em 22 jan.2016.

A carga psíquica do trabalho (I. Domingues, trad.). Psicodinâmica do trabalho: contribuições da Escola Dejouriana à análise da relação prazer, sofrimento e trabalho, p. 21-32, 1994.

A loucura do trabalho: estudo de psicopatologia do trabalho $5^{a}$ edição Ed.Cortez São Paulo 1998.

Uma nova visão do sofrimento humano nas organizações. O indivíduo na organização: dimensões esquecidas, v. 1, p. 149-173 In: CHANLAT, Jean-François et al. O indivíduo na organização: dimensões esquecidas. Atlas, 1996.

Avaliação do trabalho submetida à

prova do real - Crítica aos fundamentos da avaliação. In: Sznelwar, L. I.; Mascia, F. L. Trabalho, Tecnologia e Organização. São Paulo: Editora Blucher, 2008.

DURAND, Marina. Doença ocupacional: psicanálise e relações de trabalho, São Paulo: Escuta, 2001.

GAULEJAC, Vincent de. Gestão como doença social: ideologia, poder gerencialista e fragmentação social. 4.ed. São Paulo: Editora Ideias e Letras, 2014.

GIL, Antonio Carlos. Como elaborar projetos de pesquisa. 4. ed. São Paulo: Atlas, 2005.

LANCMAN, S., SZNELWAR, L., UCHIDA, S. \& TUACEK, T. A. O trabalho na rua e a exposição à violência no trabalho: um estudo com agentes de trânsito. Interface: Comunicação, Saúde e Educação, v. 11, n. 21, p. 79-92, 2007. Disponível em <http://www.scielosp. org/pdf/icse/v11n21/v11n21ao8.pdf > acesso em 12 ago. 2015.

MENDES, Ana Magnólia Bezerra. TAMAYO, Álvaro Valores e vivências de prazer-sofrimento no contexto organizacional. Psico USF, v. 6, n. 1, p. 39-46, 2001. Disponível em <http://pepsic. bvsalud.org/scielo.php?pid=S1413-82712001000100006\&script=sci_ arttext\&tlng=en> acesso em 20 jul. 2016. 
MENDES, René. DIAS, Elizabeth Costa. Da medicina do trabalho à saúde do trabalhado. Rev. Saúde Publ. 25(5):341p,1991. Disponível em <http://www.cienciasecognicao. org/pdf/v14_3/m253.pdf > acesso em 12 mai. 2016

MENDES, René. Patologia do Trabalho. Rio de Janeiro: Atheneu, 1995.

MORRONE, L. C., et al. Saúde e Segurança do Trabalho de Servidores Públicos Estaduais: resultados iniciais de um programa em São Paulo. Revista Brasileira de Medicina do Trabalho, Belo Horizonte, v. 2, n. 2, p. 94-102, 2004.

NUNES, A. V. L.; LINS, S. L. B. Servidores públicos federais: uma análise do prazer e sofrimento no trabalho. Psicologia: Organização e Trabalho, Brasília, v. 9, n. 1, p. 51-67, 2009. Disponível em $<$ http://www.e-publicacoes.uerj.br/index. php/revispsi/article/view/11082> acesso em 12 ago 2016.

PIRES, José Calixto de Souza; MACEDO, Kátia Barbosa. Cultura Organizacional em Organizações Públicas no Brasil. Rio de Janeiro, 2006. Disponível em: <http://www.scielo.br/ pdf/rap/v4oni/v4oniao5.pdf > acesso em: o1 Out. 2016.

RICHARDSON, Roberto Jarry e colaboradores. Pesquisa social: métodos e técnicas. $3^{\mathrm{a}}$ ed. São Paulo: Atlas, 2009.

SILVA, Edith Seligmann. Pesquisas brasileiras em saúde mental e trabalho. In: seminário Nacional de Saúde e Trabalho, 1 , Ribeirão Preto, 1990. Anais. Ribeirão Preto. EERP-USP,1991.

SILVA, Edith Seligmann; STEINER, Maria Helena C. de Figueiredo. SILVA, Moacir Carlos da. ANGERAMI, Valdemar Augusto. Crise, trabalho e saúde mental no Brasil. São Paulo: Traço,1994.

SIQUEIRA, Marcus Vinícius Soares, MENDES, Ana Magnólia. Gestão de Pessoas no setor público e a reprodução do discurso do setor privado. Revista do Serviço Público. Brasília. 6o(3):241-250 Jul/Set 2009. Disponível em <http://www.enap. gov.br/index.php?option=com docman\&task=doc_view\&gid=3402> acesso em 19 ago 2015.

SOUZA, A.L. Saúde mental e trabalho: dois enforque. Rev. Bras. Saúde Ocupacional, 20 (75), 65-71,1992. Disponível em <http:// bases.bireme.br/cgi-bin/wxislind.exe/iah/online/?IsisScript=iah/iah. lang $=$ \&\&nextAction=lnk\&exprSearch=113846\&indexSearch=ID> acesso em 20 out. 2016.

UNIVERSIDADE FEDERAL DE PERNAMBUCO. Disponível em: $<$ https://www.ufpe.br/ufpenova/> acesso em o3 de jun. 2015. 